\title{
Growth retardation induced by dexamethasone is associated with increased apoptosis of the growth plate chondrocytes
}

\author{
D Chrysis, E M Ritzen and L Sävendahl
}

Department of Woman and Child Health, Pediatric Endocrine Unit, Astrid Lindgren Children's Hospital, Karolinska Institute, SE-171 76 Stockholm, Sweden (Requests for offprints should be addressed to D Chrysis; Email: Dionisios.Chrysis@kbh.ki.se)

\begin{abstract}
Glucocorticoids cause significant growth retardation in mammals and humans and decreased proliferation of chondrocytes has been considered as the main local mechanism. Death by apoptosis is an important regulator of homeostasis in multicellular organisms. Here we chose to study the role of apoptosis in growth retardation caused by glucocorticoid treatment. We treated 7 -week-old male rats with dexamethasone $(5 \mathrm{mg} / \mathrm{kg}$ /day) for 7 days. Apoptosis was studied in tibiae growth plates by the TUNEL method. Immunoreactivity for parathyroid hormone-related peptide (PTHrP), caspase-3, and the anti-apoptotic proteins $\mathrm{Bcl}-2$ and $\mathrm{Bcl}-\mathrm{x}$ was also studied. Apoptosis was mainly localized in terminal hypertropic chondrocytes (THCs) in both control and dexamethasonetreated animals. Dexamethasone caused an increase in apoptosis which was fourfold in THCs $(2 \cdot 45 \pm 0.12$ vs
\end{abstract}

$0.62 \pm 0.09$ apoptotic cells $/ \mathrm{mm}$ growth plate, $P<0 \cdot 001)$ and 18 -fold in proliferative chondrocytes $(0 \cdot 18 \pm 0 \cdot 04$ vs $0 \cdot 01 \pm 0 \cdot 007$ apoptotic cells $/ \mathrm{mm}$ growth plate, $P<0 \cdot 001)$. Increased apoptosis after dexamethasone treatment was accompanied by increased immunoreactivity for caspase-3 and decreased immunoreactivity for the anti-apoptotic proteins $\mathrm{Bcl}-2$ and $\mathrm{Bcl}-\mathrm{x}$, which further supports our apoptosis results. Dexamethasone also decreased the immunoreactivity for PTHrP, suggesting a role in the mechanism by which glucocorticoids induce apoptosis in the growth plate. We conclude that apoptosis is one mechanism involved in growth retardation induced by glucocorticoids. Premature loss of resting/proliferative chondrocytes by apoptosis could contribute to incomplete catch-up seen after prolonged glucocorticoid treatment.

Journal of Endocrinology (2003) 176, 331-337

\section{Introduction}

Impaired longitudinal growth is a well-established side effect of glucocorticoid treatment in humans and animals (Altman et al. 1992, Allen 1996). The decreased growth is accompanied by morphological changes in the growth plate. It becomes thinner (Altman et al. 1992, Annefeld 1992), which has been attributed to decreased proliferation of the chondrocytes (Kember \& Walker 1971, Annefeld 1992). Glucocorticoids also alter the synthetic capability of chondrocytes with consequent alterations in the cartilage matrix (Annefeld 1992) and enhanced formation of electron-dense, dark-staining degenerateappearing chondrocytes (Dearden et al. 1986).

Multiple mechanisms, both endocrine and paracrine, have been implicated as the cause of growth retardation caused by glucocorticoids. Alterations of the growth hormone/insulin-like growth factor-I (GH/IGF-I) axis at multiple levels (Allen 1996, Mehls et al. 2001) have been described. In addition to systemic effects, glucocorticoids also have local effects on the growth plate, the structure responsible for longitudinal bone growth (Baron et al. 1994). Decreased proliferation of epiphyseal chondrocytes and alterations in the local production of GH/IGF-I have been reported as possible mechanisms (Kember \& Walker 1971, Annefeld 1992, Mehls et al. 2001).

Apoptosis acts as an important regulator of cell and tissue homeostasis by eliminating cells through a genetically programmed cell death. It has been suggested that apoptosis plays a role in growth plate homeostasis during development (Chrysis et al. 2002) and that apoptosis is the fate of the terminal hypertropic chondrocytes (Franum \& Wilsman 1987, Gibson et al. 1995). Furthermore, strong evidence that apoptosis is a regulator of growth plate homeostasis comes from in vivo experiments. As an example, mice with targeted disruptions of both alleles for the anti-apoptotic protein $\mathrm{Bcl}-2$ have short limbs and accelerated ossification of their growth plates (Amling et al. 1997). In addition, two chondrodysplastic conditions (parathyroid hormone-related peptide (PTHrP) knockout mice and activating mutations of the fibroblast growth factor-3 (FGFR-3)) are associated with increased apoptosis of the growth plate chondrocytes (Amizuka et al. 1994, Legeai-Mallet et al. 1998).

In a multicellular organism or tissue, growth is accomplished when cell proliferation exceeds cell death. 
Therefore, one could assume that cell death or apoptosis plays a role in growth retardation after glucocorticoid treatment. Indeed, based on the TUNEL method, increased apoptosis of the terminal hypertropic chondrocytes (THCs) has been reported in growth plates of rats after corticosterone administration (Silvestrini et al. 2000). However, conflicting results have been reported concerning the magnitude and location of apoptosis in the growth plate, based solely on the TUNEL method (Bronckers et al. 1996, Aizawa et al. 1997, Gibson 1998). In addition, the underlying mechanisms and the role of apoptosis in the growth plate after glucocorticoid treatment have not been elucidated. Therefore, we studied apoptosis in the growth plate after glucocorticoid treatment following an integrated approach. We studied not only apoptosis by the TUNEL method but also proteins important in the apoptotic pathway such as caspase-3 (one of the executors of apoptosis), and the anti-apoptotic proteins, $\mathrm{Bcl}-2$ and Bcl-x. Furthermore, because Bcl-2 lies downstream after PTHrP signaling we hypothesized that apoptosis induced by glucocorticoids is associated with decreased expression of PTHrP.

\section{Materials and Methods}

\section{Animals and sample preparation}

After approval by the local ethical committee, 7-week-old male Sprague Dawley rats (B\&K Universal, Sollentuna, Sweden) were housed in our animal care facility under a 12-h light, 12-h darkness schedule; food pellets were available ad libitum. After an adaptation period, 5 animals received dexamethasone $(5 \mathrm{mg} / \mathrm{kg}$ body weight, s.c.) for 7 days, whereas the control group of 5 animals received vehicle only. Tibiae were removed and the upper part was fixed in $4 \%$ formaldehyde in $0 \cdot 1 \mathrm{M}$ phosphate buffer, $\mathrm{pH} 7 \cdot 3$, for $18 \mathrm{~h}$ at $4{ }^{\circ} \mathrm{C}$. After fixation, specimens were decalcified in 5\% EDTA and were then paraffin embedded. Sections, $5 \mu \mathrm{m}$ thick, were cut longitudinally and mounted on histological glass slides (Superfrost +/+; Menzel-Gloeser, Braunschweig, Germany). On each slide, two sections were mounted, one from each group, so that all samples were treated under the same conditions during TUNEL and immunohistochemistry. Slides were dried at $37^{\circ} \mathrm{C}$ overnight.

\section{Determination of growth rate}

For the determination of growth rate, the fluorescent marker calcein was administered i.p. as a single injection $(10 \mathrm{mg} / \mathrm{kg})$ at the start of a separate experiment which included 6 animals divided into two groups of 3 animals each. One group received vehicle during the 7 days of the experiment, whereas the other group received dexamethasone. Proximal tibiae were prepared as described above, non-decalcified tissues were embedded in methylmethacrylate blocks and $5 \mu \mathrm{m}$ thick sections were cut longitudinally. The distance between the proximal borders of the calcein and the chondro-osseous junction of the growth plate was measured; this corresponds to the growth accomplished during 7 days.

\section{Detection of apoptosis}

Apoptotic cells in the growth plates were identified by terminal deoxynucleotidyl transferase (TdT)-mediated deoxy-UTP nick end labeling (TUNEL), according to the manufacturer's instructions (TdT-FragEL kit; Oncogene Research Products, Boston, MA, USA) with slight modifications (Chrysis et al. 2002): deparaffinized and rehydrated sections were treated with proteinase K (20 $\mathrm{mcg} / \mathrm{ml}$ ) at $37^{\circ} \mathrm{C}$ for $10 \mathrm{~min}$ instead of $20 \mathrm{~min}$. Treatment of sections with DNAse labeled all cells, whereas sections treated with distilled water instead of TdT were negative. At least 5 sections from each animal, $25 \mu \mathrm{m}$ apart (to avoid counting the same cells twice) were used to determine the number of apoptotic cells. The number of apoptotic chondrocytes was counted in the growth plate. Only cells in closed lacunae were counted and were expressed as their number per mm length of the chondro-osseous junction. The length of the chondro-osseous junction from each section was measured by the Image-Pro image analysis system (Media Cybernetics, Silver Spring, MD, USA).

\section{Immunohistochemistry}

The rabbit caspase-3 polyclonal antibody was purchased from Santa Cruz Biotechnology Inc. (1:100; Santa Cruz Biotechnology, Inc., Santa Cruz, CA, USA), the Bcl-2 rabbit polyclonal antibody was from Upstate Biotechnology (1:600; Upstate Biotechnology, Lake Placid, NY, USA), and the rabbit polyclonal Bcl-x antibody was from Transduction Laboratories (1:500; Becton Dickinson AB, Stockholm, Sweden). For the immunodetection of PTHrP a rabbit polyclonal antibody raised against amino acids 34-53 of human PTHrP was used (1:80; Oncogene Science, Cambridge, MA, USA). Control experiments were carried out with omission of the primary antibodies, incubation with non-specific rabbit $\operatorname{IgG}$ and competition of the primary antibody with corresponding peptide when available (PTHrP).

Sections were dewaxed in xylene and rehydrated in graded alcohol baths. Antigen retrieval was performed in $0.01 \mathrm{M}$ citrate buffer $(\mathrm{pH} 6.0)$ at $95-98^{\circ} \mathrm{C}$ for $20 \mathrm{~min}$ (for caspase-3 only) or with neuraminidase digestion for PTHrP $(0.025 \mathrm{U} / \mathrm{ml}$ neuraminidase for $50 \mathrm{~min}$ at room temperature). Immunohistochemistry was carried out as previously described (Chrysis et al. 2002). Biotinylated goat anti-rabbit $\operatorname{IgG}(1: 1000)$ was purchased from Jackson Immunoresearch Lab. (West Grove, PA, USA), 
avidin-conjugated peroxidase was purchased from Vector Laboratories (Burlingame, CA, USA), and a DAB-kit which generates a brown color for the detection of peroxidase activity was from Vector Laboratories. Digital microphotographs were captured by a Nikon Eclipse 800 microscope (Nikon, Bergström Instruments, Stockholm, Sweden) equipped with a Hamamatsu Orca IIIf CCD camera (Hamamatsu Inc, Stockholm, Sweden).

Immunopositive chondrocytes were detected by automatic thresholding using an image analysis system (Image-Pro; Media Cybernetics). For each antibody, at least 300 cells were analyzed in two separate sections of each specimen. Immunopositive cells are expressed as a percentage of the total number of cells analyzed in the proliferative and hypertropic zones respectively. For each antibody, all slides were processed in parallel in order for comparisons to be valid.

\section{Statistical analysis}

Results are expressed as means \pm s.E. Differences between groups were tested by Student's t-test. $P<0.05$ was considered significant.

\section{Results}

\section{Body weight and growth rate}

Before treatment was initiated, body weight was similar in the control $(199.6 \pm 4.6 \mathrm{~g})$ and in the dexamethasonetreated $(197 \cdot 0 \pm 2 \cdot 5 \mathrm{~g})$ group of animals. When killed after 7 days of treatment, body weight was increased by $32 \%$ in the control group $(263.1 \pm 5 \cdot 0 \mathrm{~g})$, whereas the dexamethasone group had lost $23 \%$ of the initial body weight $(152.3 \pm 2.9 \mathrm{~g}, P<0 \cdot 001 \mathrm{vs}$ control). Growth rate over the 7 -day period of treatment was significantly higher in controls compared with dexamethasone-treated animals $(207 \pm 14 \mu \mathrm{m} /$ day and $68 \pm 5 \mu \mathrm{m} /$ day respectively, $P<0 \cdot 001)$.

\section{Apoptosis}

Seven days of treatment with dexamethasone increased the number of apoptotic chondrocytes in all layers of the growth plate (Fig. 1). In both control and dexamethasonetreated animals most of the apoptotic chondrocytes were THCs. Compared with controls, dexamethasone caused a fourfold increase in apoptosis in THCs $(2 \cdot 45 \pm 0.12$ vs $0.62 \pm 0.09$ apoptotic cells $/ \mathrm{mm}$ growth plate, $P<0 \cdot 001)$. Apoptotic proliferative chondrocytes were rare in sections from control animals and only occasional apoptotic cells were observed in a few sections. In contrast, sections from dexamethasone-treated animals regularly had some apoptotic proliferative chondrocytes, mainly early proliferative
(Fig. 1), resulting in an 18 -fold increase $(0 \cdot 18 \pm 0 \cdot 04$ vs $0 \cdot 01 \pm 0 \cdot 007$ apoptotic cells $/ \mathrm{mm}$ growth plate, $P<0 \cdot 001)$ compared with controls.

\section{Caspase-3}

In control sections, caspase- 3 immunoreactivity was localized in proliferative and early hypertropic chondrocytes with no staining in mature and THCs. Dexamethasone treatment caused a significant increase in caspase-3 immunoreactivity in all layers of the growth plate and, more significantly, mature chondrocytes and THCs were also immunopositive (Fig. 1, Table 1).

\section{$B c l-2$ and $B c l-x$}

Immunoreactivity for the anti-apoptotic protein, Bcl-2, was localized throughout the growth plate in sections from control animals, although it was less abundant in mature and was almost absent in late/THCs (Fig. 1). Dexamethasone treatment caused a dramatic decrease in Bcl-2 immunoreactivity in all layers of the growth plate (Fig. 1, Table 1).

Immunoreactivity for Bcl-x, another anti-apoptotic protein, was localized mainly in late proliferative and hypertropic chondrocytes, especially at the interface between the proliferative and hypertropic zones (Fig. 1). Dexamethasone caused a significant decrease in Bcl-x immunoreactivity throughout the whole growth plate (Fig. 1, Table 1).

\section{PTHrP}

In control animals, PTHrP immunoreactivity was present in all layers of the growth plate but was more prominent in the hypertropic and resting zones (Fig. 1). Dexamethasone treatment caused a significant decrease in PTHrP immunoreactivity in all layers (Fig. 1, Table 1). Similar results were obtained with a second PTHrP antibody (mouse monoclonal antibody raised against amino acids 38-64 of human PTHrP; Oncogene Science).

\section{Discussion}

We report that dexamethasone treatment increases apoptosis in growth plate chondrocytes. The vast majority of the apoptotic cells were THCs and to a lesser extent early proliferative chondrocytes. In addition, increased apoptosis was associated with increased expression of caspase-3, and decreased expression of the anti-apoptotic proteins Bcl-2 and $\mathrm{Bcl}-\mathrm{x}$, which further support the activation of apoptotic signals in the growth plate after dexamethasone treatment.

Growth retardation after glucocorticoid treatment is characterized by decreased proliferation of the growth 


\section{Control (200x) Dexa (400x)}
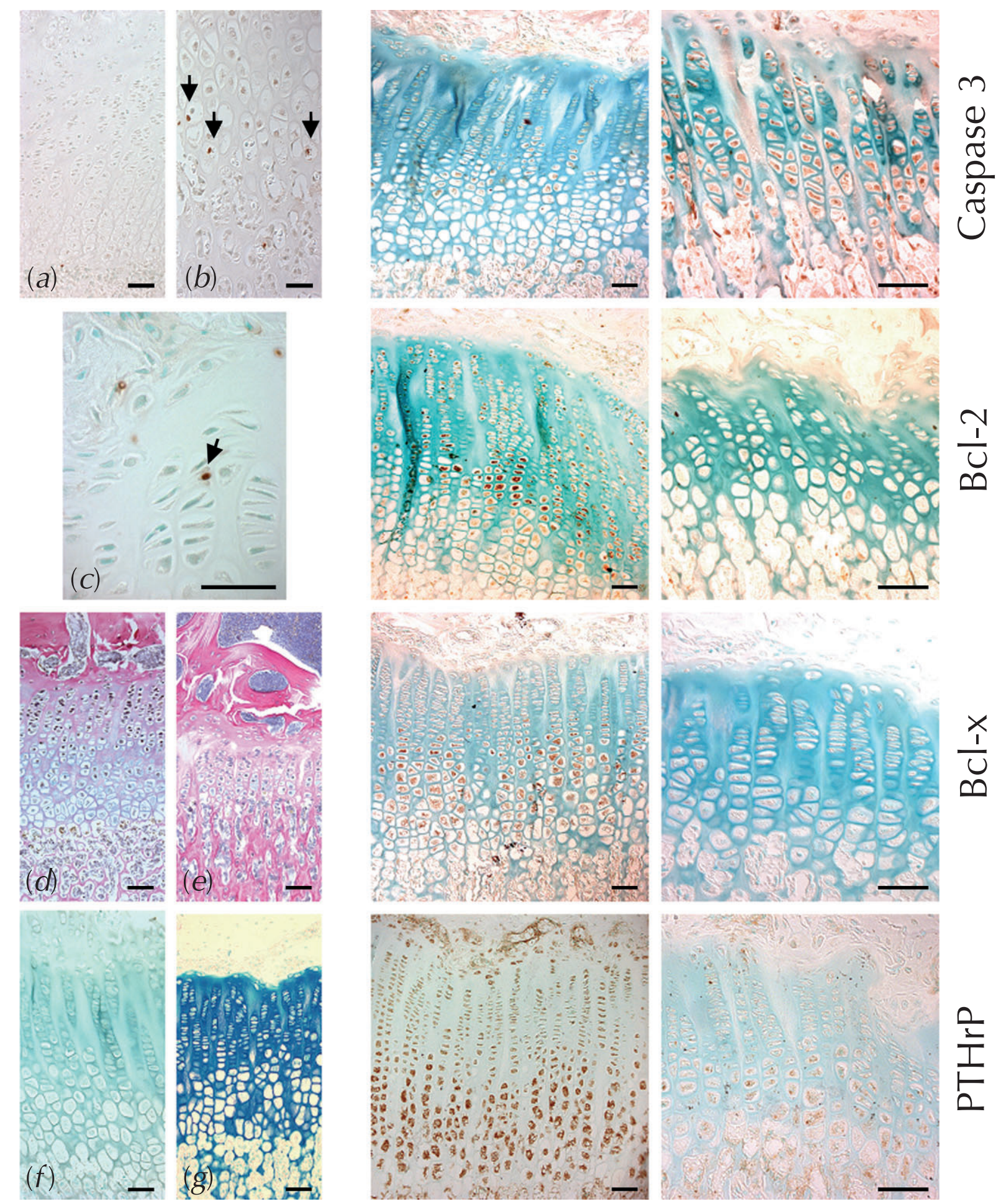
Table 1 Percentage (mean \pm S.D.) of immunoreactive chondrocytes in the different zones in control and dexamethasone (Dexa)treated rats

\begin{tabular}{|c|c|c|c|c|}
\hline & \multicolumn{2}{|c|}{ Proliferative } & \multicolumn{2}{|c|}{ Hypertropic } \\
\hline & Control & Dexa & Control & Dexa \\
\hline Caspase-3 & $45 \pm 8$ & $77 \pm 11^{*}$ & $18 \pm 2$ & $94 \pm 9^{*}$ \\
\hline $\mathrm{Bcl}-2$ & $78 \pm 6$ & $2 \cdot 0 \pm 0 \cdot 1^{*}$ & $39 \pm 5$ & $5 \cdot 0 \pm 1 \cdot 0^{*}$ \\
\hline $\mathrm{Bcl}-\mathrm{x}$ & $35 \pm 2$ & $1 \cdot 0 \pm 0 \cdot 1^{*}$ & $81 \pm 13$ & $3 \cdot 0 \pm 0 \cdot 1^{*}$ \\
\hline PTHrP & $73 \pm 9$ & $32 \pm 4^{*}$ & $94 \pm 12$ & $58 \pm 7^{*}$ \\
\hline
\end{tabular}

${ }^{*} P<0 \cdot 001$ vs control.

plate chondrocytes, which has been considered to be the main local mechanism by which glucocorticoids decrease growth rate and thickness of the growth plate (Kember \& Walker 1971, Annefeld 1992). As growth is the excess of cell proliferation compared with cell death, glucocorticoids could also slow growth by inducing apoptosis of growth plate chondrocytes. Indeed, we found that the number of apoptotic THCs was significantly increased in dexamethasone-treated compared with control animals. Therefore, the combination of decreased proliferation and increased cell death could, together, explain glucocorticoid-induced growth retardation. Our data are further supported by a previously published study in older rats where increased apoptosis was observed after long treatment ( 3 weeks) with corticosterone (Silvestrini et al. 2000). Based on several observations we believe that the observed increased rate of apoptosis in the THCs reflects a real increase rather than an artifact. First, the immunoreactivity for caspase-3 was increased concomitantly with apoptosis and more specifically in the hypertropic and THCs where apoptosis was mainly observed. Secondly, both anti-apoptotic proteins, $\mathrm{Bcl}-2$ and $\mathrm{Bcl}-\mathrm{x}$, were dramatically decreased in dexamethasone-treated rats. Finally, apoptosis was increased by dexamethasone not only in THCs but also in early proliferative chondrocytes although less frequently. The antibody for caspase- 3 recognizes both proactive and active caspase- 3 and therefore the immunoreactivity does not indicate which form is present. The several-fold increase in caspase-3 in the hypertropic chondrocytes where most apoptosis was observed, in association with the remarkable decrease in the antiapoptotic proteins $\mathrm{Bcl}-2$ and $\mathrm{Bcl}-\mathrm{x}$, could suggest an increase in the activation of the apoptotic pathway and therefore activation of caspases rather than an increase in the proactive caspase alone.

Decreased growth rate is associated with a longer lifespan of the growth plate chondrocytes (Huzniker et al. 1987). Therefore, one could argue that the observed increase in apoptosis after dexamethasone treatment is an artifact as the cells remain longer as THCs and thereby are more likely to be detected as apoptotic. We believe that this hypothesis is not valid because the final stage of apoptosis, as detected by TUNEL, is irreversible and there are no indications from the literature that this stage can be elongated. Moreover, our integrated data from caspase-3, $\mathrm{Bcl}-2$, and $\mathrm{Bcl}-\mathrm{x}$ clearly show that the growth plate is more susceptible to apoptosis after dexamethasone treatment.

In vivo experiments have shown the importance of apoptosis for normal growth. Bcl-2 knockout mice (Amling et al. 1997) have short limbs with skeletal deformities. These experiments indicate that despite the existence of several members of the $\mathrm{Bcl}$ family of proteins in the growth plate, $\mathrm{Bcl}-2$ has a pivotal role in growth plate apoptosis. In addition, elegant in vivo and in vitro experiments have shown that $\mathrm{Bcl}-2$ lies downstream of the PTHrP signaling pathway (Amling et al. 1997). PTHrP stimulates the expression of Bcl-2 protein in the growth plate chondrocytes leading to delayed maturation. On the other hand, mice homozygous for PTHrP gene ablation (Amizuka et al. 1994, 1996), similar to Bcl-2 knock-out mice, have skeletal deformities with decreased proliferation and accelerated maturation of chondrocytes, and a large population of immature chondrocytes were apoptotic. Furthermore, the survival role of PTHrP has been confirmed not only in vivo but also in vitro (Henderson et al. 1995). Based on these data, we hypothesized that the decreased proliferation of chondrocytes after dexamethasone treatment, as well as the decreased immunoreactivity for Bcl-2 and consequently increased apoptosis could be mediated through diminished expression of $\mathrm{PTHrP}$ in the growth plate. Indeed, with two different antibodies we observed that the immunoreactivity for PTHrP was decreased after dexamethasone treatment. Our data

\footnotetext{
Figure 1 Representative microphotographs of TUNEL assays from growth plates from control (a) and dexamethasone-treated (b, c) rats. Apoptosis was observed mainly in terminal hypertropic chondrocytes (THCs) $(a, b)$ and dexamethasone caused a fourfold increase in apoptosis of THCs (b). Arrows indicate apoptotic chondrocytes in closed lacunae. Apoptotic proliferative chondrocytes were rare and an 18 -fold increase was observed after dexamethasone (c). Bars represent $100 \mu \mathrm{m}$. Representative microphotographs of caspase-3, Bcl-2, $\mathrm{Bcl}-\mathrm{x}$ and PTHrP immunohistochemistry from tibial growth plates in control and dexamethasone-treated rats are shown. Microphotographs from control sections have a magnification of $200 \times$, whereas those from the dexamethasone-treated group have a magnification of $400 \times$ because the height of the growth plate is significantly smaller than that of controls. Immunoreactivity for caspase- 3 was increased in the dexamethasone-treated group, whereas for $\mathrm{Bcl}-2, \mathrm{Bcl}-\mathrm{x}$ and PTHrP it was decreased. Microphotographs of growth plates stained with Alcian blue/van Gieson show the differences in the growth plate height in control $(d)$ and dexamethasone (e) groups at $200 \times$ magnification. The specificity of primary antibodies was assessed by replacement of primary antibodies with normal rabbit serum $(f)$ and with preabsorption of the PTHrP antibody with blocking peptide $(g)$.
} 
suggest an underlying mechanism for apoptosis induced by glucocorticoids which involves the $\mathrm{PTHrP} / \mathrm{Bcl}-2$ pathway. This is further supported by many in vitro studies in different cell lines, where dexamethasone downregulates the expression of parathyroid hormone (PTH)/PTHrP (Glatz et al. 1994, Southby et al. 1996).

Discontinuation of systemic glucocorticoid treatment in humans and mammals or treatment of Cushing's syndrome in children leads to catch-up growth which is often incomplete and does not fully compensate for the growth deficit induced by glucocortioid excess (Baron et al. 1994, Magiakou et al. 1994). We observed an increased number of apoptotic resting/early proliferative chondrocytes after dexamethasone treatment. Apoptotic resting/early proliferative chondrocytes were rare in occasional sections from control animals but after dexamethasone treatment an 18 -fold increase was observed. It has been suggested that the observed catch-up growth after dexamethasone treatment is due to delayed senescence of the growth plate as the chondrocytes have undergone fewer replications due to the inhibitory effect of dexamethasone on cell proliferation (Gafni et al. 2001). In every dynamic model of growth there are two parameters for optimal growth: cell proliferation and cell death. Therefore, we propose that cell death should be considered in the model of growth plate senescence. Premature loss of resting or early proliferative cells could diminish the growth potential in spite of increased numbers of remaining replications of the chondrocytes. This premature loss of resting/early proliferative chondrocytes could account for the incomplete catch-up growth after glucocorticoid excess and for a final height which is often shorter than the predicted height.

In summary, we show that growth retardation after dexamethasone treatment is associated with increased apoptosis in the growth plate, which occurs through a down-regulation of the anti-apoptotic proteins $\mathrm{Bcl}-2$ and $\mathrm{Bcl}-\mathrm{x}$ and an increase in caspase-3. Our data support a model of glucocorticoid-induced apoptosis where the inhibition of the PTHrP expression causes a reduction of the anti-apoptotic protein Bcl-2 which triggers death signals in the growth plate chondrocytes. Finally, we propose that incomplete catch-up growth after prolonged exposure to supraphysiological concentrations of glucocorticoids could be secondary to premature loss of resting/ proliferative chondrocytes by apoptosis.

\section{Acknowledgements}

This study was supported by the Swedish MRC (K200172X-13508-02B), the Karolinska Institute Research Foundation, the Cornell Foundation, the Sven Jerring Foundation, Wenner Gren Foundation, Wera Ekströms Stiftelsen, Erik Rönnbergs Foundation, and Stiftelsen Frimurare Barnhuset in Stockholm.

\section{References}

Aizawa T, Kokubun S \& Tanaka Y 1997 Apoptosis and proliferation of growth plate chondrocytes in rabbits. Journal of Bone and Joint Surgery 79B 483-486.

Allen DB 1996 Growth suppression by glucocorticoid therapy. Endocrinology and Metabolism Clinics of North America 25 699-717.

Altman A, Hochberg Z \& Silberman M 1992 Interactions between growth hormone and dexamethasone in skeletal growth and bone structure of the young mouse. Calcified Tissue International $\mathbf{5 1}$ 298-304.

Amizuka N, Warshawsky H, Henderson JE, Goltzman D \& Karaplis AC 1994 Parathyroid hormone-related peptide-depleted mice show abnormal epiphyseal cartilage development and altered endochondral bone formation. Journal of Cell Biology 126 1611-1623.

Amizuka N, Henderson JE, Hoshi K, Warshawsky H, Ozawa H, Goltzman D \& Karaplis AC 1996 Programmed cell death of chondrocytes and aberrant chondrogenesis in mice homozygous for parathyroid hormone-related peptide gene deletion. Endocrinology $1375055-5067$.

Amling M, Neff L, Tanaka S, Inoue D, Kuida K, Weir E, Philbrick WM, Broadus AE \& Baron R 1997 Bcl-2 lies downstream of parathyroid hormone-related peptide in a signaling pathway that regulates chondrocyte maturation during skeletal development. Journal of Cell Biology 136 205-213.

Annefeld M 1992 Changes in rat epiphyseal cartilage after treatment with dexamethasone and glucosaminoglycan-peptide complex. Pathology Research and Practice 188 649-652.

Baron J, Klein KO, Colli MJ, Yanovski JA, Novosad JA, Bacher JD \& Cutler GB Jr 1994 Catch-up growth after glucocorticoid excess: a mechanism intrinsic to the growth plate. Endocrinology 135 1367-1371.

Bronckers ALJJ, Goei W, Luo G, Karsenty G, D'Souza RN, Lyaruu DM \& Burger EH 1996 DNA fragmentation during bone formation in neonatal rodents assessed by transferase-mediated end labeling. Journal of Bone and Mineral Research 11 1281-1291.

Chrysis D, Nilsson O, Ritzen EM \& Savendahl L 2002 Apoptosis is developmentally regulated in rat growth plate. Endocrine $\mathbf{1 8}$ 271-278.

Dearden LC, Mosier HD, Brundage Jr M, Thai C \& Jansons R 1986 The effects of different steroids on costal and epiphyseal cartilage of fetal and adult rats. Cell and Tissue Research 246 401-412.

Franum CE \& Wilsman NJ 1987 Cellular turnover at the chondroosseous junction of growth plate cartilage: analysis by serial sections at the light microscopical level. Anatomical Record 219 221-232.

Gafni RI, Weise M, Robrecht DT, Meyers JL, Barnes KM, De-Levi S \& Baron J 2001 Catch-up growth is associated with delayed senescence of the growth plate in rabbits. Pediatric Research $\mathbf{5 0}$ 618-623.

Gibson G 1998 Active role of chondrocyte apoptosis in endochondral ossification. Microscopy Research and Technique 43 191-204.

Gibson GJ, Kohler WJ \& Schaffler MB 1995 Chondrocyte apoptosis in endochondral ossification of chick sterna. Developmental Dynamics 203 468-476.

Glatz JA, Heath JK, Southby J, O'Keeffe LM, Kiriyama T, Moseley JM, Martin TJ \& Gillespie MT 1994 Dexamethasone regulation of parathyroid hormone-related protein $(\mathrm{PTHrP})$ expression in a squamous cancer cell line. Molecular and Cell Endocrinology 101 295-306.

Henderson JE, Amizuka N, Warshawsky H, Biasotto D, Lanske BMK, Goltzman D \& Karaplis AC 1995 Nucleolar localization of parathyroid hormone-related peptide enhances survival of chondrocytes under conditions that promote apoptotic cell death. Molecular and Cellular Biology 15 4064-4075.

Huzniker EB, Schenk RK \& Cruz-Orive LM 1987 Quantitation of chondrocyte performance in growth-plate cartilage during longitudinal bone growth. Journal of Bone and Joint Surgery 69 $162-173$. 
Kember NF \& Walker KVR 1971 Control of bone growth in rats. Nature 229 428-429.

Legeai-Mallet L, Benoist-Lasselin C, Delizoide AL, Munnich A \& Bonaventure J 1998 Fibroblast growth factor receptor 3 mutations promote apoptosis but do not alter chondrocyte proliferation in thanatophoric dysplasia. Journal of Biological Chemistry 273 13007-13014.

Magiakou MA, Mastorakos G \& Chrousos GP 1994 Final stature in patients with endogenous Cushing's syndrome. Journal of Clinical Endocrinology and Metabolism 79 1082-1085.

Mehls O, Himmele R, Homme M, Kiepe D \& Klaus G 2001 The interaction of glucocorticoids with the growth hormone-insulin-like growth factor axis and its effects on growth plate chondrocytes and bone cells. Journal of Pediatric Endocrinology and Metabolism 14 1475-1482.
Silvestrini G, Ballanti P, Patacchioli FR, Mocetti P, Di Grezia R, Wedard BM, Angelucci L \& Bonucci E 2000 Evaluation of apoptosis and the glucocorticoid receptor in the cartilage growth plate and metaphyseal bone cells of rats after high-dose teatment with corticosterone. Bone 26 33-42.

Southby J, Murphy LM, Martin TJ \& Gillespie MT 1996 Cell-specific and regulator-induced promoter usage and messenger ribonucleic acid splicing for parathyroid hormone-related protein. Endocrinology 137 1349-1357.

Received 30 September 2002

Accepted 16 December 2002 